\title{
Citrus fruits as a treasure trove of active natural metabolites that potentially provide benefits for human health
}

\author{
Xinmiao Lv ${ }^{1 \dagger}$, Siyu Zhao ${ }^{1 \dagger}$, Zhangchi Ning ${ }^{1}$, Honglian Zeng ${ }^{1}$, Yisong Shu ${ }^{1}$, Ou Tao ${ }^{1}$, Cheng Xiao ${ }^{2 *}$, Cheng Lu Lu, $^{34^{*}}$ \\ and Yuanyan Liu ${ }^{1 *}$
}

\begin{abstract}
Citrus fruits, which are cultivated worldwide, have been recognized as some of the most high-consumption fruits in terms of energy, nutrients and health supplements. What is more, a number of these fruits have been used as traditional medicinal herbs to cure diseases in several Asian countries. Numerous studies have focused on Citrus secondary metabolites as well as bioactivities and have been intended to develop new chemotherapeutic or complementary medicine in recent decades. Citrus-derived secondary metabolites, including flavonoids, alkaloids, limonoids, coumarins, carotenoids, phenolic acids and essential oils, are of vital importance to human health due to their active properties. These characteristics include anti-oxidative, anti-inflammatory, anti-cancer, as well as cardiovascular protective effects, neuroprotective effects, etc. This review summarizes the global distribution and taxonomy, numerous secondary metabolites and bioactivities of Citrus fruits to provide a reference for further study. Flavonoids as characteristic bioactive metabolites in Citrus fruits are mainly introduced.
\end{abstract}

Keywords: Citrus fruits, Secondary metabolites, Bioactivities, Human health, Flavonoids

\section{Background}

Citrus fruits, which belong to the genus Citrus of the family Rutaceae, are of various forms and sizes (from round to oblong), commonly known as oranges, mandarins, limes, lemons, grapefruits and citrons. The sensory attributes of fruits (color, sweet taste, bitterness, and astringency) constitute decisive organoleptic and commercial properties [1]. Citrus species are consumed mainly as fresh or raw materials for juices or are canned as segments. Additionally, Citrus fruits can also be used in the food, beverage, cosmetic and pharmaceutical

\footnotetext{
*Correspondence: xc2002812@126.com; Iv_cheng0816@163.com yyliu_1980@163.com

${ }^{+}$Xinmiao Lv and Siyu Zhao contributed equally to this work

'School of Chinese Materia Medica, Beijing University of Chinese Medicine, Beijing 100029, China

${ }^{2}$ Institute of Clinical Medicine, China-Japan Friendship Hospital, Beijing 100029, China

${ }^{3}$ Institute of Basic Research in Clinical Medicine, China Academy of Chinese Medical Sciences, Beijing 100700, China

Full list of author information is available at the end of the article
}

industries as additives, spices, cosmetic ingredients and chemoprophylactic drugs, respectively [2, 3].

Citrus fruits are good sources of nutrition with an ample amount of vitamin C. Besides, the fruits are abundant in other macronutrients, including sugars, dietary fiber, potassium, folate, calcium, thiamin, niacin, vitamin B6, phosphorus, magnesium, copper, riboflavin and pantothenic acid [4]. However, secondary metabolites are an especially popular topic in the present research. These constituents, also known as phytochemicals, are small molecules that are not strictly necessarily for the survival of the plants but represent pharmacological activity. Citrus fruits contain a number of secondary metabolites, such as flavonoids, alkaloids, coumarins, limonoids, carotenoids, phenol acids and essential oils. These active secondary metabolites show several bioactivities of vital importance to human health, including anti-oxidative, anti-inflammatory, anti-cancer, as well as cardiovascular protective effects, neuroprotective effects, etc. In addition, Citrus fruits have been used as traditional medicinal herbs in several Asian countries, such as China, Japan 
and Korea. Nine traditional Chinese medicines have been recorded in the Chinese Pharmacopoeia for appropriate medical use from six Citrus species [5]: C. reticulata Blanco, C. medica L. var. sarcodactylis Swingle, C. medica L., C. wilsonii Tanaka, Citrus aurantium L. and C. sinensis Osbeck. These peels or whole fruits (mature or immature) are known to treat indigestion, cough, skin inflammation, muscle pain, and ringworm infections, as well as to lower blood pressure.

This review summarizes the global distribution and taxonomy, numerous secondary metabolites and bioactivities related to human health of Citrus fruits. Especially, flavonoids as the main characteristic metabolites in Citrus fruits, which can provide benefit for human health based on their multiple bioactivities. Then, the secondary metabolites variation among different species and fruit parts were mentioned to provide a better guide for our daily use and related industries.

\section{Distribution and taxonomy}

According to statistics of FAOSTAT [6], Citrus species are grown all over the world in more than 140 countries, with more than 8.7 million hectares and about 131 million tons of fruits produced in 2012. And China, Brazil, the U.S.A., India, Mexico, and Spain are the world's leading Citrus fruit-producing countries (see Fig. 1a), representing close to two-thirds of global production. In China, citriculture has existed traditionally, and the Citrus varieties have been naturally selected [7] (see Fig. 1b): (1) C. aurantifolia (Christm.) Swingle, (2) C. aurantium L., (3) C. hongheensis Ye et al., (4) C. hystrix DC., (5) C. ichangensis Swingle, (6) C. junos Sieb. ex Tanaka, (7) C. limon (L.) Burm. f., (8) C. limonia Osb., (9) C. macroptera Montrous., (10) C. maxima (Burm.) Merr., (11) C. medica L., (12) C. paradisi Macf., (13) C. reticulata Blanco, (14) C. sinensis (L.) Osb.

The genus Citrus belongs to the subtribe Citrinae, tribe Citreae, subfamily Aurantioideae of the family Rutaceae. However, continual taxonomic study appears to be very complicated and controversial, mainly due to sexual compatibility between Citrus species and related genera, the high frequency of bud mutations, apomixis (e.g., adventitious embryony) [8]. Consequently, there has been no consensus among taxonomists as to the actual number of Citrus species. The most widely accepted taxonomic systems for Citrus are those of Swingle and Reece [9] and Tanaka [10], who recognized 16 and 162 species, respectively. Later, phylogenetic analysis indicated only three true species within the cultivated Citrus [11], i.e., C. medica L. (citron), C. reticulata Blanco (mandarin) and C. maxima (Burm.) Merr. (pummelo). In order to be convenient, the existing taxonomic systems are combined currently.
Because morphological characters are of limited use, studies have mainly focused on new taxonomy methods, i.e., chemotaxonomy. 66 Citrus species and near-Citrus relatives can be cited in accordance with Tanaka's classification system with 24 flavonoids [12]. Flavanones were used as chemotaxonomic markers to distinguish $77 \mathrm{Zhi}$ shi (traditional Chinese medicine) samples from three Citrus species [13]. Another study suggested that the content of certain monoterpenes could be as taxonomic markers between C. sinensis Osbeck and C. junos Sieb. ex Tanaka [14].

\section{Active secondary metabolites}

Plentiful active natural metabolites including flavonoids, alkaloids, coumarins, limonoids, carotenoids, phenolic acids and essential oils, have been found in Citrus fruits. Tables in additional files have summarized these secondary metabolites isolated from peel, pulp, seed, pressed oil, juice or whole fruit from 31 common species to give a systematical profile. By these at least, the types of Citrus-derived secondary metabolites vary among different Citrus species and different fruit parts. Moreover, flavanones, synephrine, auraptene and limonin are the most dominants among the flavonoids, alkaloids, coumarins and limonoids groups, respectively.

In Additional file 1, 48 types of flavonoids from 22 common Citrus species of different fruit parts (peel, pulp, seed, pressed oil, juice or whole fruit) have been summarized. These flavonoids belong to the five classes: flavones, flavonols, flavanones, flavanonols and polymethoxylated flavones. Anthocyanins, an uncommon class of flavonoid, only appears in blood oranges of limited data in different fruit parts [15]. Among Citrusderived flavonoids, flavanones comprise approximately $95 \%$ of the total flavonoids [16]. And flavones, flavonols and polymethoxylated flavones present in lower concentration. In addition, some of flavonoids are unique to Citrus plants. Citrus-derived flavonoids are present in glycoside or aglycone forms, and usually do not occur naturally as aglycones but rather as glycosides, in which the aglycones are linked to a sugar moiety [17]. Among the aglycone forms, naringenin, hesperetin, apigenin, nobiletin, tangeretin and quercetin are widely detected (see Additional file 1). For glycoside forms, O-glycosides, C-glycosides, rutinosides, glucosides and neohesperidosides are common. Naringin (neohesperidoside), neohesperidin (neohesperidoside), narirutin (rutinoside), and hesperidin (rutinoside) are commonly present in major quantities. Sinensetin, isosinensetin, nobiletin, tangeretin, which all belong to polymethoxylated flavones, exist only as aglycones because the binding sites for sugar moieties are not occupied by hydroxyl moieties [18]. 

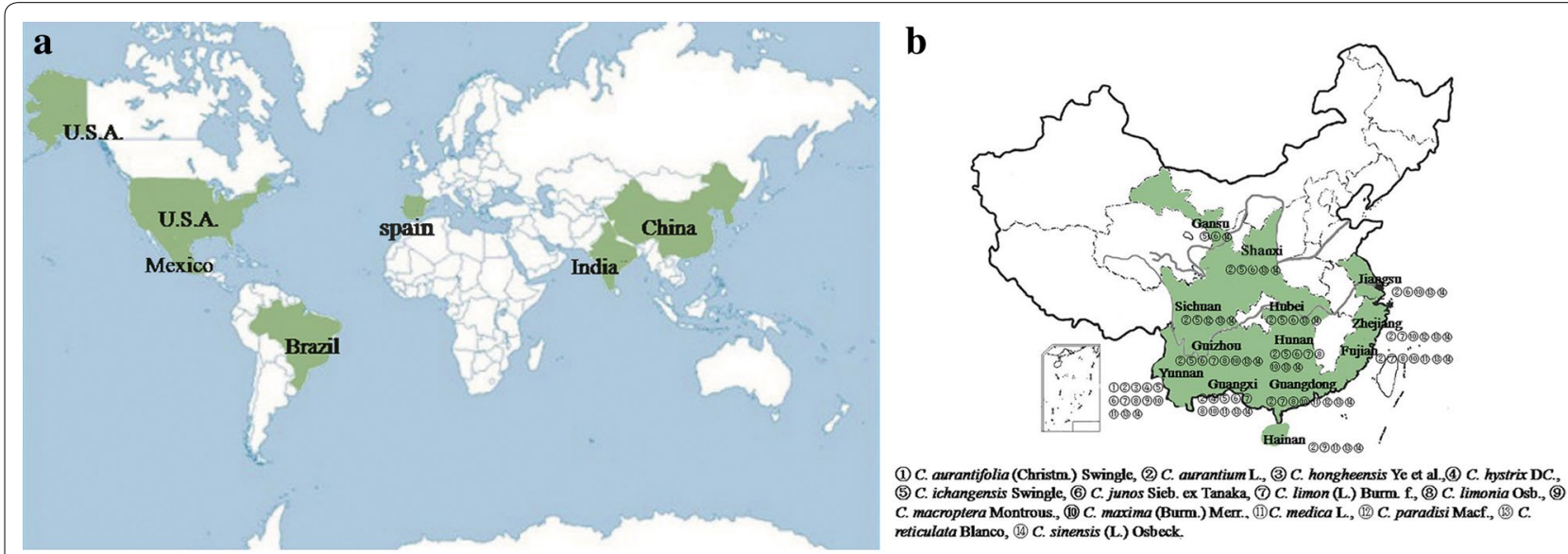

Fig. 1 a Top six Citrus fruits-producing countries in the world. Citrus species are grown in 140 countries, though production shows geographical concentration in certain areas. China, Brazil, the USA, India, Mexico, and Spain are the world's top 6 Citrus fruit-producing countries, representing close to two-thirds of global production. China is the first leading country as producers which had produced 32,221,345 tons of Citrus fruit in 2012. Brazil is the second production country of Citrus fruits with 20,258,507 tons in 2012. And the USA. India, Mexico and Spain also play dominant roles in Citrus production which all produced more than 5,000,00 tons in 2012. b Distribution of 14 Citrus-varieties in the major Citrus-producing provinces of China. There are 14 Citrus varieties distributed in 13 provinces in China. (1) C. aurantifolia (Christm.) Swingle is mainly distributed in Yunnan province; (2) C. aurantium L. is mainly distributed in Fujian, Guangdong, Guangxi, Guizhou, Hainan, Hubei, Hunan, Jiangsu, Shaanxi, Sichuan, Yunnan, Zhejiang, provinces; (3) C. hongheensis Ye et al. is mainly distributed in Yunnan province; (4) C. hystrix DC. is mainly distributed in Guangxi, Yunnan province; (5) C. ichangensis Swingle is mainly distributed in Gansu, Guangxi, Guizhou, Hubei, Hunan, Shaanxi, Sichuan, Yunnan provinces; (6) C. junos Sieb. ex Tanaka is mainly distributed in Gansu, Guangxi, Guizhou, Hubei, Hunan, Jiangsu, Shaanxi, Yunnan provinces; ( 7 ) C. limon (L.) Burm. f. is mainly distributed in Fujian, Guangdong, Guangxi, Guizhou, Hunan, Yunnan, Zhejiang provinces; (8) C. limonia Osb. is mainly distributed in Fujian, Guangdong, Guangxi, Guizhou, Hunan, Yunnan provinces; (9) C. macroptera Montrous. is mainly distributed in Hainan, Yunnan provinces; (10) C. maxima (Burm.) Merr. is mainly distributed in Fujian, Guangdong, Guangxi, Guizhou, Hunan, Jiangsu, Yunnan, Zhejiang provinces; (11) C. medica L. is mainly distributed in Fujian, Guangdong, Guangxi, Hainan, Yunnan provinces; (12) C. paradisi Macf. is mainly distributed in Guangdong, Sichuan, Zhejiang provinces; (13) C. reticulata Blanco is mainly distributed in Fujian, Guangdong, Guangxi, Guizhou, Hainan, Hubei, Hunan, Jiangsu, Shaanxi, Sichuan, Yunnan, Zhejiang provinces; (14) C. sinensis (L.) Osb. is mainly distributed in Fujian, Gansu, Guangdong, Guangxi, Guizhou, Hainan, Hubei, Hunan, Jiangsu, Shaanxi, Sichuan, Yunnan, Zhejiang provinces

In Additional file 2, alkaloids, coumarins, limonoids, carotenoids, phenolic acids and essential oils have also been well summarized from different Citrus species and different fruit parts. Active alkaloids are abundant in $C$. aurantium compared to other Citrus species, especially synephrine, which comprises more than $85 \%$ of the total protoalkaloid content [19]. Additionally, N-methyltyramine has been found at much higher concentrations than octopamine, tyramine or hordenine [20]. Coumarins are commonly found in Citrus plants (high concentration in peels). Auraptene (7-geranyloxycoumarin) is a major coumarin in Citrus plants. Limonoids are unique compounds occurring in the Meliaceae and Rutaceae family. Citrus (a genus in the family Rutaceae) limonoids are highly oxygenated triterpenoids, which are present as aglycones, glucosides, and A-ring lactones. Also, Citrus limonoids are the metabolic precursors to limonoid aglycones and glucosides [21]. Limonin and limonin glucoside (see Additional file 2) are the most abundant limonoids for the majority of Citrus species. Carotenoids are a large family of isoprenoid compounds that impart yellow, orange, and red pigments to many plants as well as the yellow-to-orange color of Citrus fruits. Lutein, zeaxanthin and $\beta$-cryptoxanthin, $\beta$-carotene, can be found in significant quantities in tangerines and oranges ([22], see Additional file 2). Investigations have shown that the majority of phenolic acids in Citrus fruits are present in bound forms [23].

In Additional file 3, Citrus-derived volatile compounds from 15 common Citrus Species have been summarized. These compounds are roughly divided into 6 groups: monoterpene hydrocarbons, sesquiterpene hydrocarbons, alcohols, aldehydes, esters \& ketones and Oxides. These volatile compounds are mainly come from peels of Citrus fruits that have many oil chambers of unique aroma flavors, differ depending on the species and variety.

\section{Bioactivities}

Owing to these metabolites, Citrus fruits exhibit plentiful bioactivities including anti-oxidant, anti-inflammatory, anti-cancer, anti-microbial and anti-allergy activities, as well as cardiovascular effect, neuroprotective effect, hepatoprotective effect, obesity control, etc. Note that 
flavonoids (especially flavanone, flavanonol and methoxylated flavones) are more active compared to other secondary metabolites in Citrus for their remarkable various bioactivities. Studies on plentiful bioactivities from hesperetin/hesperidin (flavanone) [24-28], naringenin/ naringin (flavanone) [29-34], tangeretin (polymethoxylatedflavone) [35-37] and nobiletin (polymethoxylatedflavone) [36, 38-41] have been widely reported.

\section{Anti-oxidant}

Reactive oxygen species (ROS) are chemically derived from oxygen such as superoxide anion, hydroxyl radicals and hydrogen peroxide in living organisms by amount of metabolism pathways, while anti-oxidant system is able to defend against it to keep balance [42]. However, modern lifestyle involves a number of factors that may raise the level of ROS which play a critical role in the pathogenesis of various diseases such as aging, arthritis, cancer, inflammation, and heart disease, and cause oxidative stress. Citrus extracts such as Citrus karna peel extracts, Citrus limetta peel extracts and Citrus bergamia juice extracts were found to have potential antioxidant bioactivity [43-45]. Citrus fruits are reported to have a good anti-oxidant ability especially because of their phenolic compounds with poly-hydroxyl groups, including phenolic acids, flavonoids and their derivatives [46]. The primary anti-oxidant mechanisms of phenolic compounds are listed below:

- Direct absorption and neutralization of free radicals [47].

- Inhibition of enzymes associated with ROS pathways: NADPH oxidase, xanthine oxidase and myeloperoxidase [48].

- Enhancement of the activities of human anti-oxidant enzymes: superoxide dismutase, catalase, etc. [49].

\section{Flavonoids}

The juices from green and ripe chinotto (C. myrtifolia Raf.), which were full of flavonoid, was tested by DPPH. radical bleaching and superoxide-anion scavenging, and it was shown that immature chinotto fruits, in particular, yield a juice with a remarkable anti-oxidant power [50]. The anti-oxidant activity of the flavonoid mixture isolated from the Citrus peel was determined in terms of the DPPH. and ABTS ${ }^{+}$scavenging and the reducing power assay in a concentration range from 25 to $500 \mathrm{mg} / \mathrm{L}$, and its anti-oxidant activity increased in a dose-dependent manner [51]. Sun et al. [52] using FRAP, $\mathrm{DPPH}$, and ABTS assays detected immature fruits drops of nine Citrus varieties cultivated in China and determined that the anti-oxidant activity, which varied significantly among the species, was highest in Citrus poonensis
Hort. ex Tanaka and Citrus unshiu Marc. cv Owari and lowest in Citrus paradise Macf. Changshanhuyou, Citrus grandis (L.) Osbeck cv Foyou, and Citurs limon (L.) Burm.f. cv Eureka. Different anti-oxidant assays have applied to evaluate anti-oxidant activity. For instance, quercetagetin showed strong DPPH radical-scavenging activity $\left(\mathrm{IC}_{50} 7.89 \mathrm{~mol} \mathrm{~L}^{-1}\right)$ but much lower hydroxyl radical-scavenging activity $\left(\mathrm{IC}_{50} 203.82 \mu \mathrm{mol} \mathrm{\textrm {L } ^ { - 1 }}\right)$. In vivo, hesperetin was administered orally and acted as a potent antioxidative agent against $\mathrm{Cd}$-induced testicular toxicity in rats [24]. Hesperetin increased the glutathione and glutathione dependent enzymes in the testes of rats, by which it effectively reduced the $\mathrm{Cd}$-induced oxidative stress and restored the activities of ATPases. Aranganathan and Nalini reported that hesperetin exerted an anti-lipoperoxidative effect and thereby restored the membrane-bound ATPase activity in Cd-intoxicated rat testes [53].

\section{Phenolic acids}

There were positive correlations among the results of the anti-oxidant capacities and total phenolic acids contents of the Tarhana samples [54]. The anti-oxidant potency composite index showed wide variations, ranging from 58.84 to 98.89 in the 14 studied wild mandarin genotypes native to China, due to different phenolic compounds' levels, including phenolic acids. Ogiwara et al. [55] found that caffeic, chlorogenic, and ferulic acids scavenged various radicals, such as superoxide anions and hydroxy radicals. Citric acids from Citrus have been found to show anti-oxidant activity in lipopolysaccharide (LPS)-treated mice [56]. Korani et al. [57] demonstrated that gallic acid has a beneficial activity against 2VO-induced cognitive deficits via enhancement of the cerebral anti-oxidant defense. Among the phenolic acid group, gallic acid with three hydroxyl groups on the aromatic ring was the strongest anti-oxidant [58]. In contrast, the monosubstituted phenolic acids ( $p$-coumaric acid, $o$-coumaric acid, and 4-OH-phenylacetic acid) showed very low activity. In addition, the radical-scavenging activities of phenolic acids are related to their hydroxyl group characteristics in the order: gallic $>$ gentisic $>$ syringic $>$ caffeic $>$ protocatechuic $>$ sinapic $>$ ferulic $>$ isoferulic $>$ vanillic $>$ p-coumaric $>$ o-coumaric $>$ m-coumaric $>$ salicylic $\gg$ p-hydroxybenzoic [59].

\section{Essential oils}

Singh et al. [60] reported that monoterpenic essential oils were natural anti-oxidants. Choi et al. [61] found that the radical-scavenging activity of 34 types of Citrus essential oils on DPPH ranged from 17.7 to $64 \%$. These activities were determined to be higher when the oils contained geraniol, terpinolene and $\gamma$-terpinene. However, the 
bioactivity of the essential oils generally resulted from a complex interaction between its constituents, which produced both synergistic and antagonistic responses [62].

\section{Coumarins}

The accumulating data from studies revealed that dihydroxycoumarins were better anti-oxidants than monohydroxycoumarins and that the $\mathrm{OH}$ groups positioned near $\mathrm{C} 6$ and $\mathrm{C} 7$ in the coumarin skeleton played an important role in the inhibition of mushroom tyrosinase [63].

\section{Anti-inflammatory}

Inflammation is a very complex response that is mediated by inflammatory cytokines including tumor necrosis factor-alpha (TNF- $\alpha)$, interleukin- $1 \beta$ and interleukin-6 as well as a cascade of molecular mediators including inducible nitric oxide synthase (iNOS), cyclooxygenase-2 (COX-2), which are all closely regulated by the organism. And these inflammatory cytokines are active in the pathogenesis of various chronic inflammatory diseases such as multiple sclerosis, Parkinson's disease, Alzheimer's disease and colon cancer [64]. Orange (C. aurantium L.) peel extract was found to suppress UVB-induced COX-2 expression and PGE2 production in $\mathrm{HaCaT}$ cells, and acted as a peroxisome proliferator-activated receptor (PPAR)-c agonist [65]. Flavonoids, coumarin and volatile oil from Citrus fruit are showing anti-inflammatory activity, which can be used as supplement to protect against or ameliorate this chronic inflammatory diseases.

\section{Flavonoids}

Naringin reduced lipopolysaccharide- or infectioninduced endotoxin shock in mice, attenuated chronic pulmonary neutrophilic inflammation in cigarette smoke-exposed rats [29]. And its aglycone, naringenin, exerted anti-inflammatory activities in macrophages and in human blood [66]. Hesperidin exerted noticeable in vivo anti-inflammatory systemic effects in mouse models of LPS-induced lung inflammation and of endotoxin-induced infection [25], in rat models of rheumatoid arthritis and against inflammation in mouse skin [26]. Nobiletin dose-dependently reduced the nitric oxide (NO) levels and decreased iNOS expression at the protein, mRNA and antisense transcript levels [38]. Sudachitin had been found to inhibit NO production by suppressing the expression of iNOs in LPS-stimulated macrophages, to exhibit anti-inflammatory activity, and was a more potent anti-inflammatory agent than nobiletin [67]. In addition, quercetin was known to possess strong anti-inflammatory capacities [68]. Data suggested that flavone suppresses iNOS expression via a mechanism that was similar to that of nobiletin and that the flavone skeleton was essential for the suppression of $\mathrm{NO}$ and iNOS [69]. Although many types of flavonoids exhibited anti-inflammatory activity, hesperidin and diosmin did not cause significant decreases in NO production in RAW264.7 cells [38].

\section{Essential oils}

C. latifolia Tanaka volatile oil and its main constituent limonene decreased the infiltration of peritoneal exudate leukocytes and the number of polymorphonuclear leukocytes in zymosan-induced peritonitis, and additionally reduced TNF- $\alpha$ levels (but not IL-10 levels) in the peritoneal exudates [70]. Citropten and bergapten from bergamot oil, were found as strong inhibitors of interleukin-8 (IL-8) expression, and could be proposed as potential anti-inflammatory molecules to reduce lung inflammation in patients with cystic fibrosis [71].

\section{Coumarins}

Auraptene exhibited anti-inflammatory activities by suppressing the production of inflammatory factors that mediated the interaction between adipocytes and macrophages [72]. Another coumarin, imperatorin, also showed anti-inflammatory activity in LPS-stimulated mouse macrophage (RAW264.7) in vitro and a carrageenan-induced mouse paw edema model in vivo [73]. Besides, imperatorin blocked the protein expression of iNOs and COX-2 in LPS-stimulated RAW 264.7cells. 7, 8-dimethoxycoumarin $(100 \mathrm{mg} / \mathrm{kg})$ from C. decumana peels showed ameliorative effect on gastric inflammation [74].

\section{Anti-cancer}

Citrus fruits are high in secondary metabolites, including flavonoids, limonoids, and coumarins, which are associated with a reduced risk of cancer, including gastric cancer, breast cancer, lung tumorigenesis, colonic tumorigenesis, hepatocarcinogenesis, and hematopoietic malignancies, etc. [75-81] Chang and Jia found Ougan (Citrus reticulata cv. Suavissima) flavedo extract exhibited potential anti-tumor effects by its inhibitory effect on epithelial-to-mesenchymal transition and interfering with the canonical TGF- 31 -SMAD-Snail/Slug axis [82].

\section{Flavonoids}

Pre- and post-treatment with naringenin effectively suppressed NDEA-initiated heap-tocarcinoma and the associated preneoplastic lesions by modulating xenobiotic-metabolizing enzymes, alleviating lipid peroxidation, and decreasing the levels of liver-marker enzymes [30]. Additionally, naringenin has also been documented in cadmium-induced hepatotoxicity and MNNG-induced gastric carcinogenesis [31, 32]. Supplemented hesperetin to DMH-treated rats suppressed the formation of 
aberrant crypt foci and significantly reduced the activity of bacterial enzymes in colon cancer [27]. The results clearly revealed that dietary hesperetin possessed antiproliferative ability against chemically-induced colon tumorigenesis [28]. Apigenin was able to cause cell death of BxPC-3 and PANC-1 human pancreatic cancer cells by the inhibition of the GSK-3 $\beta / \mathrm{NF}-\mathrm{kB}$ signaling cascade leading to the induction of apoptosis [83]. Poncirin showed a significant in vitro inhibitory effect on the growth of the human gastric cancer cells, SGC-7901, in a dose-dependent manner [84]. Tangeretin caused arrest of the cell-cycle progression at the G1 phase and growth inhibition in the incubation of colon adenocarcinoma COLO 205 cells [35]. Quercetin was found to exhibit a suppressive effective in colon carcinogenesis and human cervical cancer cells, but it was found to be ineffective in mammary carcinogenesis [85]. Nobiletin (methoxylated flavonoids) exerted inhibitory effects on the cell adhesion, invasion, and migration abilities of a highly metastatic AGS cells under non-cytotoxic concentrations through Ras/PI3K/AKT signaling pathway [39]. Polymethoxyflavones from C. tamurana, C. tachibana and $C$. kinokuni show anticancer activity [43] The cytotoxicity of methoxylated flavonoids was higher than that of the hydroxylated analogues [86]. However, it was found that 5-demethylnobiletin exhibited much stronger inhibitory effects on the growth of various cancer cells than nobiletin, suggesting the pivotal role of the hydroxyl group at the 5-position in the enhanced anti-cancer activity [87].

\section{Limonoid}

Limonoids, including methyl nomilinate, isoobacunoic acid, isolimonexic acid, and limonexic acid, were evaluated for their biological effects on SW480 human colon adenocarcinoma cells [88]. Among them, methyl nomilinate was the most potent inhibitor of cell metabolic activity in MTT and EdU incorporation assays. A study reported that the anti-proliferative properties of limonoids from C. limon L. Burm were mediated by caspase-7-dependent pathways in breast cancer cells [89]. Moreover, their cytotoxic effect was more pronounced in estrogen-responsive breast cancer cells. The combinations of limonoids and curcumin were effective in inducing apoptosis in SW480 cells [90]. Furthermore, limonoids and curcumin exhibited synergistic inhibition of proliferation of colon cancer cells, which was supported by the total caspase- 3 activity in the cells treated with combinations of limonoids and curcumin.

\section{Coumarins}

Oltipraz, auraptene, imperatorin, isopimpinellin, and auraptene all significantly increased liver cytosolic GST activities in Nrf2 heterozygous mice, suggesting anti-carcinogenic activities [91]. Besides, 5-geranyloxy-7-methoxycoumarin, limettin, and isopimpinellin inhibited human colon cancer (SW-480) cell proliferation, with 5-geranyloxy-7-methoxycoumar showing the highest inhibition activity $(67 \%)$ at $25 \mu \mathrm{m}$ [92].

\section{Carotenoids}

$\beta$-Cryptoxanthin was reported to inhibit mouse skin tumorigenesis and rat colon carcinogenesis [93].

\section{Cardiovascular protective effects}

Large epidemiological studies frequently link increased consumption of flavonoid-rich foods with reduced cardiovascular morbidity and mortality [94] through the impact on blood lipid, blood glucose and vascular function. Herwandhani Putri found that Citrus hystrix kaffir lime's peel ethanolic extract had potency to be developed as cardioprotector agent in chemotherapy [95].

\section{Impact on blood lipid}

Flavonoids A number of experiments suggested that Citrus-derived flavonoids may lower blood cholesterol $(\mathrm{CH})$ and triglyceride (TG). Full methoxylation of the A-ring of Citrus flavonoids appeared to be the optimal structure to express potent effects on modulating hepatic lipid metabolism via primarily suppressing apoB-containing lipoprotein secretion using HepG2 cells [96]. Tangeretin and nobiletin, which have the optimal molecular structure, may lower blood $\mathrm{CH}$ and TG concentrations, whereas other Citrus flavonoids without a fully methoxylated A-ring may have virtually no or only weak lipid-lowering effects in humans such as hesperidin and naringin [36]. In high-fat fed $\mathrm{Ldlr}^{-/}$ mice, the addition of nobiletin resulted in a dramatic reduction in both hepatic and intestinal TG accumulation, attenuation of very low-density lipoprotein(LDL)TG secretion and normalization of insulin sensitivity [40]. However, a study demonstrated that hydroxylated PMFs, such as $3^{\prime}, 4^{\prime}$-didemethylnobiletin and 5-demethylnobiletin, were more potent than permethoxylated nobiletin in inhibiting PMA-induced scavenger receptor expression and modifying LDL uptake in THP-1 cells [97].

\section{Impact on blood glucose}

Flavonoids Citrus flavonoids (hesperidin, naringin, neohesperidin, and nobiletin) significantly inhibited amylase-catalyzed starch digestion. Moreover, naringin and neohesperidin mainly inhibited amylose digestion, whereas hesperidin and nobiletin inhibited both amylose and amylopectin digestion. These results 
demonstrated that Citrus flavonoids play important roles in preventing the progression of hyperglycemia, partly by binding to starch, increasing hepatic glycolysis and the glycogen concentration, and lowering hepatic gluconeogenesis [98]. Hesperidin, naringin, and nobiletin also exhibited antidiabetic activities, partly by lowering hepatic gluconeogenesis or improving insulin sensitivity in diabetic animals [99]. A study suggested that naringenin conferred protection against experimental diabetes through its antihyperglycemic and anti-oxidant properties in streptozotocin-nicotinamide-induced experimental diabetic rats [33]. In vivo chronic treatment of diabetic rats with naringenin could prevent the functional changes in vascular reactivity in diabetic rats through a NO-dependent and prostaglandin-independent pathway [34].

\section{Impact on vascular function}

Flavonoids Naringenin and hesperetin might exert anti-atherogenic effects partly through activating peroxisome proliferator-activated receptor and up-regulating adiponectin expression in adipocytes [100]. A study investigated the anti-atherosclerotic action and underlying mechanism of 5-demethylnobiletin in a cell-culture system and determined that 5-demethylnobiletin attenuated monocyte differentiation into macrophage and blunts foam cell formation by down regulating SR expression and activity [97]. This compound also altered the lipid homeostasis in hepatocytes by up-regulating LDL receptor expression via steroid-response element-binding protein-2 activation and down-regulating diacylglycerol acyltransferases 2 expression. In individuals with stage I hypertension, a double-blind crossover trial evaluated the effect on blood pressure of the consumption of a high-flavonoid Citrus juice compared to a low-flavonoid Citrus juice [101]. Only consumption of the high-flavonoid Citrus juice during 5 weeks resulted in a significant reduction in diastolic blood pressure $(-3.7 \mathrm{mmHg})$. However, another controlled crossover trial involving individuals with metabolic syndrome had shown an improvement in flow-mediated dilation after a 3-week supplementation with $500 \mathrm{mg}$ of hesperidin but with no effect on blood pressure [102].

\section{Neuroprotective effects}

In Ming $\mathrm{Wu}$ and Hongwu Zhang's paper, they showed both $C$. aurantium L. aqueous extract and its major constituents (naringin, hesperidin, neohesperidin, and nobiletin) had neuroprotective effect on corticosteroneinduced neurotoxicity in PC12 cells. The in vivo and in vitro results suggest that $C$. aurantium $\mathrm{L}$. aqueous extract had an antidepressant effect [103].

\section{Flavonoids}

The Citrus flavanones hesperidin, hesperetin, and neohesperidin have neuroprotective activity against $\mathrm{H}_{2} \mathrm{O}_{2}$ induced cytotoxicity in pheochromocytoma cell line (PC12 cells) by diverse mechanisms, including antioxidant activity, regulation of intracellular calciumions, and inhibition of caspase-3 activity [104]. Hwang et al. [105] tested the effect of Citrus flavonoids against oxidative stress in PC12 cells, showing neuroprotection by the modulation of Akt/PKB, c-jun N-terminal kinase and P38 activation. Meanwhile, they also found flavonoids acted more as signaling molecules than as antioxidants in this study. A pilot clinical study suggested the possibility that 1-year oral administration of decocted nobiletin-rich $C$. reticulata peel could be of benefit for improving the cognition of patients with Alzheimer's disease, with no adverse side effects [41]. A study showed that 3,5,6,7,8,3', $4^{\prime}$-heptamethoxyflavone had the ability to induce brain-derived neurotrophic factor production in astrocytes and enhance neurogenesis after brain ischemia, which may be mediated by activation of extracellular signal-regulated kinases $1 / 2$ (ERK1/2) and cAMP response element-binding protein [106].

\section{Coumarins}

Auraptene and 7-isopentenyloxycoumarin exerted protective effects against NMDA-induced excitatory neurotoxicity in mixed cortical cell cultures [107]. Using a transient global ischemia mouse model, a study showed that auraptene effectively inhibited microglia activation, COX-2 expression by astrocytes, and neuronal cell death in the hippocampus following ischemic insults [108]. Auraptene had the ability to induce the activation of ERK1/2 in not only cortical neurons but also the rat PC12 cells and was able to promote neurite outgrowth from PC12 cells.

\section{Other bioactivities}

Apart from widely reported bioactivities mentioned above, other bioactivities of Citrus fruits from latest studies have also been reviewed (see Table 1).

\section{Application of Citrus species}

Citrus species are 131 million tons of fruits produced in 2012 [6]. This large production is also relevant to the high consumption of Citrus fruits. Moreover, Citrus fruits rank first in international fruit trade in terms of its values of which cover fresh Citrus market and processed Citrus product market (such as food additives, spices, cosmetic ingredients, juice, jam, and chemotherapeutic drugs).

Given the plentiful bioactivities of Citrus fruits, the clinical use of them is of great significance. Investigation among 42,470 Japanese adults showed that Citrus 


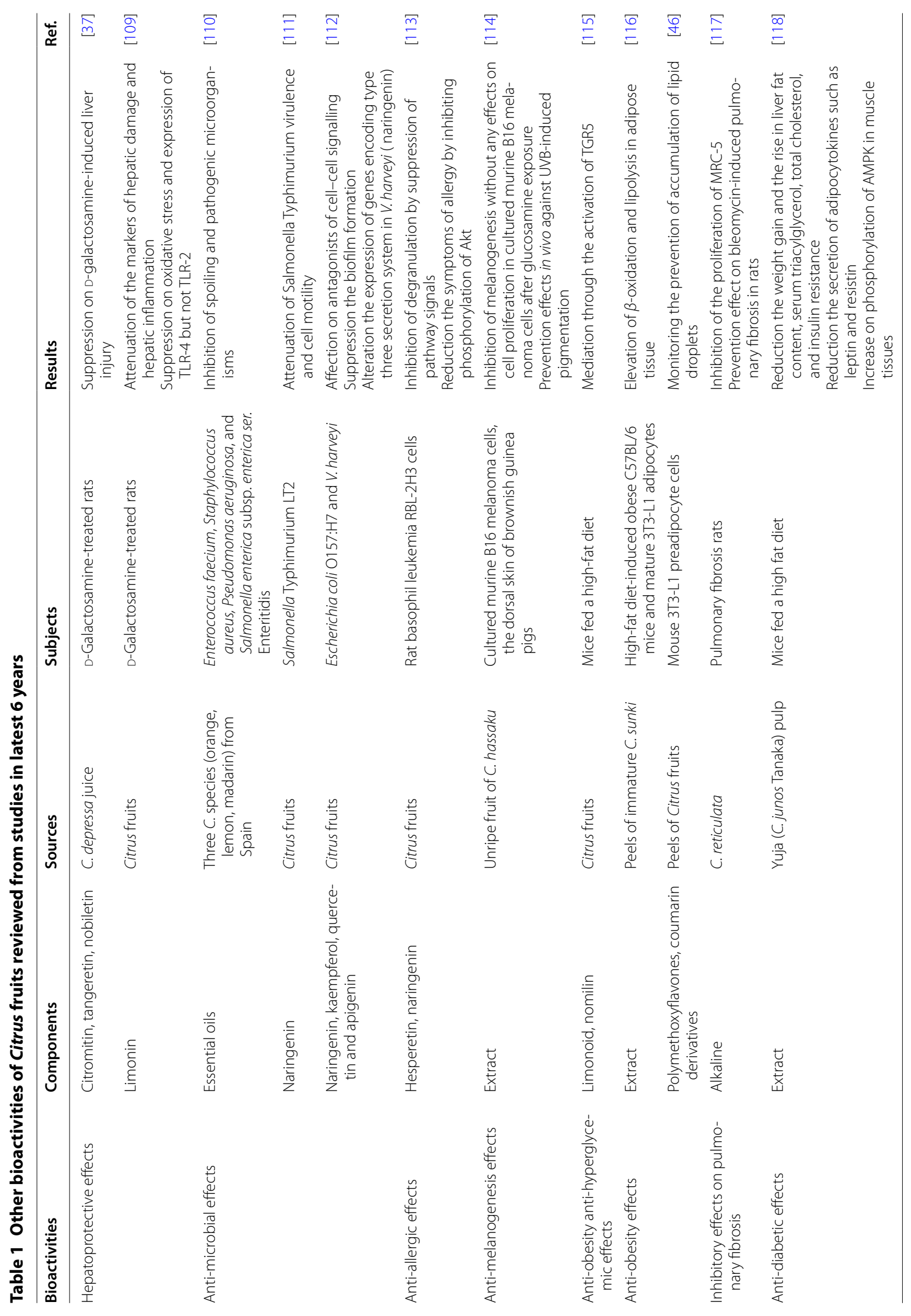




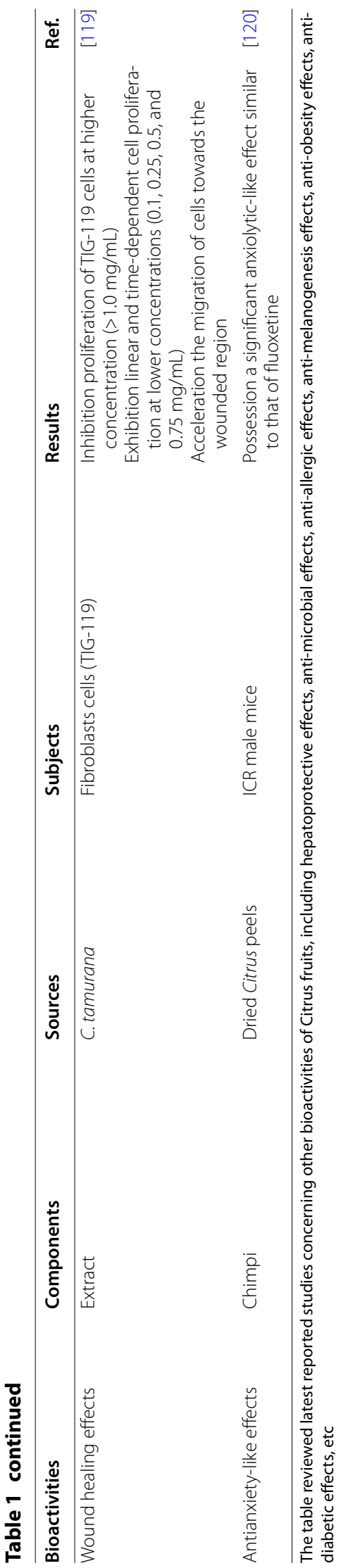


consumption was associated with reduced all-cancer incidence, especially for subjects that had simultaneously high green tea consumption [121]. A cross-sectional study (2031 elderly individuals) examined the relationship between the intake of different plant foods and cognitive performance and found Citrus fruits had the strongest associations with mean test scores (positively) [122]. Another study found hesperidin (Citrus flavonoids) presented a better balance in bone metabolism on bone health [123]. And immature peels of citrus fruit are used to treat indigestion and have demonstrated potential as a chemotherapeutic agent $[124,125]$. Many other studies have also shown that the consumption of Citrus fruits is associated with inhibition of various cancers, including colorectal, esophageal, and stomach cancer, as well as anti-stroke activity, improved blood lipid profiles and improved survival of the elderly [16]. And more and further studies are still required for Citrus species as chemotherapeutic drugs.

The consumption of Citrus fruits or juice is inversely associated with several diseases because of its abundant secondary metabolites. Almost $33 \%$ of the Citrus fruits are industrially processed for juice production, however, where about half of processed Citrus including peels, segment membrane and seeds end up as wastes [126]. These solid residues are referred to as Citrus wastes with estimated worldwide production of 15 million tons per year [127]. What's more, as reviewed in additional files, these Citrus wastes are still rich in various biologically secondary metabolites associated with human health. Citrus peel contains a high content of polymethoxylated flavones and flavanones, including primarily hesperidin, nobiletin, neohesperidin, naringin and tangeretin. A study suggested that hesperetin could be exploited as a potential functional ingredient and offered opportunities to develop new formulations of functional foods [27]. Peels are also major source of essential oil as well as carotenoids, with approximately $70 \%$ of the total fruit carotenoids, and their contents may be from two to six times higher than those of the endocarp [128]. Besides, seeds are the major sources of limonoids. Mayumi Minamisawa et al. have succeeded in extracting a large amount of limonoids from yuzu (Citrus junos) seeds which contain higher amounts of fat-soluble limonoid aglycone (330.6 mg/g of dry seed), water-soluble limonoid glycoside $(452.0 \mathrm{mg} / \mathrm{g}$ of dry seed), and oil $(40 \mathrm{mg} / \mathrm{g}$ of green seed) [129]. Citrus species are noticeably beneficial fruits for consumption daily both for their nutrients contents and multiple active metabolites with related bioactivities, which manifests it is worthwhile to develop more useful recycling approaches of Citrus wastes. The applications given by Citrus wastes may help the industrial processors to find new ways of increasing the profit by recycling bioactive compounds and also reducing the considerable problem of wastes.

\section{Conclusion and prospective}

The multiple secondary metabolites in Citrus, including flavonoids, alkaloids, coumarins, limonoids, carotenoids, phenolic acids and volatile compounds, provide a rational basis for various biological activities. Among them, flavonoids (especially flavanones, flavanonols and methoxylated flavones) exhibit more bioactivities compared to other secondary metabolites. However, all these active metabolites work synergistically to exhibit anti-oxidative, anti-inflammatory, anti-cancer, anti-microbial and antiallergy effects, as well as presenting cardiovascular protection, neuroprotective effect, hepatoprotective effect, etc. Consequently, these multiple active metabolites with various bioactivities indicate that Citrus species are beneficial fruits when eaten daily, both for their nutrients contents and as chemotherapeutic or complementary medicine to promote health. Furthermore, different species, fruit parts, stages of maturity, environmental conditions during growth, storage conditions and postharvest treatments can influence the level of active metabolites and related activities. And further investigations are required in order to make optimal use of these fruits.

\section{Additional files}

\begin{abstract}
Additional file 1: Table S1. Flavonoids isolated from Citrus species. The table summarized flavones (including polymethoxylated flavones), flavonols, flavanones and flavanonols from Citrus species including $C$. aurantifolia, C. aurantium, C. canaliculata, C. clementina, C. erythrosa, C. grandis, C. hassaku, C. hystrix, C. junos, C. kinokuni, C. leiocarpa, C. limon, C. limonimedica, C. medica, C. microcarpa, C. paradisi, C. reticulate, C. sinensis, C. suhuiensis, C. tachibana, C. tamurana and C. unshiu.

Additional file 2: Table S2. Alkaloids, coumarins, limonoids, carotenoids and phenolic acids isolated from Citrus species. The table summarized alkaloids, coumarins, limonoids, carotenoids and phenolic acids from Citrus species including C. aurantifolia, C. aurantium, C. bergamia, C. canaliculata, C. clementina, C. grandis, C. hassaku, C. junos, C. kinokuni, C. leiocarpa, C. limon, C. limonimedica, C. maxima, C. microcarpa, C. myrtifolia, C. paradisi " C. reticulate, C. sinensis, C. tachibana and C. unshiu.

Additional file 3: Table S3. Volatile compounds isolated from Citrus species. The table summarized citrus-derived volatile compounds from common Citrus Species including C. Aurantium, C. Aurantifolia, C. Medica, C. Limon, C. Bergamia, Citrus reticulata, C. Kinokuni, C. Unshiu, C. Clementina, C. Sinensis, C. Clementine $\times$ C. Tangerine, C. grandis $\times$ C. Grandis, C. Paradisi, C. Nobilis and C. depressa.
\end{abstract}

\section{Abbreviations}

PMF: polymethoxylated flavones; ROS: reactive oxygen species; LPS: lipopolysaccharide; TNF-a: tumor necrosis factor-alpha; iNOS: inducible nitric oxide synthase; COX-2: cyclooxygenase-2; NO: nitric oxide; $\mathrm{CH}$ : cholesterol; TG: triglyceride; LDL: low-density lipoprotein.

\section{Authors' contributions}

$\mathrm{YL}$ and $\mathrm{CL}$ provided the concept and designed the manuscript. $\mathrm{XL}, \mathrm{SZ}$, OT and MY did the literature research. ZN, CX and $\mathrm{HZ}$ selected and analyzed the data 
for the work. XL, CX and $\mathrm{HZ}$ drafted the manuscript. OT and MY organized the contents of manuscript and participated in discussion on views in the paper. $\mathrm{XL}, \mathrm{SZ}, \mathrm{ZN}, \mathrm{YL}$ and $\mathrm{CL}$ revised the manuscript. All authors read and approved the final manuscript.

\section{Author details}

'School of Chinese Materia Medica, Beijing University of Chinese Medicine, Beijing 100029, China. ${ }^{2}$ Institute of Clinical Medicine, China-Japan Friendship Hospital, Beijing 100029, China. ${ }^{3}$ Institute of Basic Research in Clinical Medicine, China Academy of Chinese Medical Sciences, Beijing 100700, China. ${ }^{4}$ School of Chinese Medicine, Hong Kong Baptist University, Kowloon Tong, Hong Kong SAR 999077, China.

\section{Acknowledgements}

This study was financially supported by the National Science Foundation of China (Project No. 81573569, 81470177, 81001623 and No. 81373773), Beijing Nova Program (xx2014B073) and Beijing Natural Science Foundation (No. 7142144).

\section{Competing interests}

All authors declare that they have no competing interests.

Received: 14 July 2015 Accepted: 25 November 2015 Published online: 24 December 2015

\section{References}

1. García-Salas P, Gómez-Caravaca AM, Arráez-Román D, Segura-Carretero A, Guerra-Hernández E, García-Villanova B, Fernández-Gutiérrez A (2013) Influence of technological processes on phenolic compounds, organic acids, furanic derivatives, and antioxidant activity of wholelemon powder. Food Chem 141:869-878

2. He D, Shan Y, Wu Y, Liu G, Chen B, Yao S (2011) Simultaneous determination of flavanones, hydroxycinnamic acids and alkaloids in citrus fruits by HPLC-DAD-ESI/MS. Food Chem 127:880-885

3. Kelebek H, Selli S (2011) Determination of volatile, phenolic, organic acid and sugar components in a Turkish cv. Dortyol (Citrus sinensis L. Osbeck) orange juice. J Sci Food Agric 91:1855-1862

4. Economos C, Clay WD (1999) Nutritional and health benefits of citrus fruits. Food Nutr Agric 24:11-18

5. Committee NP (2010) Pharmacopoeia of People's Republic of China, vol 2. China Medicinal Science and Technology Press, Beijing

6. Food and Agricultural Organization of the United Nations. http:// faostat3.fao.org/faostat-gateway/go/to/home/E

7. Flora Republicae Popularis Sinicae. http://frps.eflora.cn/frps/Citrus

8. Caristi C, Bellocco E, Panzera V, Toscano G, Vadala R, Leuzzi U (2003) Flavonoids detection by HPLC-DAD-MS-MS in lemon juices from Sicilian cultivars. J Agric Food Chem 51:3528-3534

9. Swingle WT (1967) The botany of Citrus and its wide relatives, vol 1. University of California Press, Berkeley

10. Tanaka T (1977) Fundamental discussion of Citrus classification. Stud Citrol 14:1-6

11. Barret H, Rhodes A (1976) A numerical taxonomic study of affinity relationships in cultivated Citrus and its close relatives. Syst Bot 1:105-136

12. Kawaii S, Tomono Y, Katase E, Ogawa K, Yano M (1999) Quantitation of flavonoid constituents in citrus fruits. J Agric Food Chem 47:3565-3571

13. Liu Z, Liu Y, Wang C, Song Z, Zha Q, Lu C, Wang C, Lu A (2012) Discrimination of Zhishi from different species using rapid-resolution liquid chromatography-diode array detection/ultraviolet (RRLC-DAD/UV) coupled with multivariate statistical analysis. J Med Plants Res 6:866-875

14. Liu Y, Liu Z, Wang C, Zha Q, Lu C, Song Z, Ning Z, Zhao S, Lu X, Lu A (2014) Study on essential oils from four species of Zhishi with gas chromatography-mass spectrometry. Chem Cent J 8:1-8

15. Aruoma OI, Landes B, Ramful-Baboolall D, Bourdon E, Neergheen-Bhujun V, Wagner KH, Bahorun T (2012) Functional benefits of citrus fruits in the management of diabetes. Prev Med 54:S12-S16

16. Peterson JJ, Beecher GR, Bhagwat SA, Dwyer JT, Gebhardt SE, Haytowitz DB, Holden JM (2006) Flavanones in grapefruit, lemons, and limes: a compilation and review of the data from the analytical literature. J Food Compost Anal 19:S74-S80
17. Chen J, Montanari AM, Widmer WW (1997) Two new polymethoxylated flavones, a class of compounds with potential anticancer activity, isolated from cold pressed dancy tangerine peel oil solids. J Agric Food Chem 45:364-368

18. Nielsen S, Breinholt V, Cornett C, Dragsted L (2000) Biotransformation of the citrus flavone tangeretin in rats. Identification of metabolites with intact flavane nucleus. Food Chem Toxicol 38:739-746

19. Stohs SJ, Preuss HG, Shara M (2011) The safety of Citrus aurantium (bitter orange) and its primary protoalkaloid p-synephrine. Phytother Res PTR 25:1421-1428

20. Percy DW, Adcock JL, Conlan XA, Barnett NW, Gange ME, Noonan LK, Henderson LC, Francis PS (2010) Determination of Citrus aurantium protoalkaloids using HPLC with acidic potassium permanganate chemiluminescence detection. Talanta 80:2191-2195

21. Manners GD (2007) Citrus limonoids: analysis, bioactivity, and biomedical prospects. J Agric Food Chem 55:8285-8294

22. Breithaupt DE, Bamedi A (2001) Carotenoid esters in vegetables and fruits: a screening with emphasis on beta-cryptoxanthin esters. J Agric Food Chem 49:2064-2070

23. Gorinstein S, Cvikrova M, Machackova I, Haruenkit R, Park YS, Jung ST, Yamamoto K, Martinez Ayala AL, Katrich E, Trakhtenberg S (2004) Characterization of antioxidant compounds in Jaffa sweeties and white grapefruits. Food Chem 84:503-510

24. Shagirtha K, Pari L (2011) Hesperetin, a citrus flavonone, protects potentially cadmium induced oxidative testicular dysfunction in rats. Ecotox environ Safe 74:2105-2111

25. Yeh CC, Kao SJ, Lin CC, Wang SD, Liu CJ, Kao ST (2007) The immunomodulation of endotoxin-induced acute lung injury by hesperidin in vivo and in vitro. Life Sci 80:1821-1831

26. Koyuncu H, Berkarda B, Baykut F, Soybir G, Alatli C, Gül H, Altun M (1998) Preventive effect of hesperidin against inflammation in CD-1 mouse skin caused by tumor promoter. Anticancer Res 19:3237-3241

27. Aranganathan S, Selvam JP, Nalini N (2008) Effect of hesperetin, a citrus flavonoid, on bacterial enzymes and carcinogen-induced aberrant crypt foci in colon cancer rats: a dose-dependent study. J Pharm Pharmacol 60:1385-1392

28. Aranganathan S, Nalini N (2013) Antiproliferative Efficacy of Hesperetin (Citrus Flavanoid) in 1, 2-Dimethylhydrazine-induced Colon Cancer. Phytother Res 27:999-1005

29. Nie YC, Wu H, Li PB, Luo YL, Long K, Xie LM, Shen JG, Su WW (2012) Antiinflammatory effects of naringin in chronic pulmonary neutrophilic inflammation in cigarette smoke-exposed rats. J Med Food 15:894-900

30. Arul D, Subramanian P (2013) Inhibitory effect of naringenin (citrus flavonone) on $\mathrm{N}$-nitrosodiethylamine induced hepatocarcinogenesis in rats. Biochem Biophys Res Commun 434:203-209

31. Ekambaram G, Rajendran P, Magesh V, Sakthisekaran D (2008) Naringenin reduces tumor size and weight lost in N-methyl- $\mathrm{N}^{\prime}$-nitro$\mathrm{N}$-nitrosoguanidine-induced gastric carcinogenesis in rats. Nutr Res 28:106-112

32. Renugadevi J, Prabu SM (2010) Cadmium-induced hepatotoxicity in rats and the protective effect of naringenin. Exp Toxicol Pathol 62:171-181

33. Annadurai T, Muralidharan A, Joseph T, Hsu M, Thomas $P$, Geraldine P (2012) Antihyperglycemic and antioxidant effects of a flavanone, naringenin, in streptozotocin-nicotinamide-induced experimental diabetic rats. J Physiol Biochem 68:307-318

34. Fallahi F, Roghani M, Moghadami S (2012) Citrus flavonoid naringenin improves aortic reactivity in streptozotocin-diabetic rats. Indian J Pharmacol 44:382

35. Pan MH, Chen WJ, Lin-Shiau SY, Ho CT, Lin JK (2002) Tangeretin induces cell-cycle G1 arrest through inhibiting cyclin-dependent kinases 2 and 4 activities as well as elevating Cdk inhibitors p21 and p27 in human colorectal carcinoma cells. Carcinogenesis 23:1677-1684

36. Demonty I, Lin Y, Zebregs YE, Vermeer MA, van der Knaap HC, Jäkel M, Trautwein EA (2010) The citrus flavonoids hesperidin and naringin do not affect serum cholesterol in moderately hypercholesterolemic men and women. J Nutr 140:1615-1620

37. Akachi T, Shiina Y, Ohishi Y, Kawaguchi T, Kawagishi H, Morita T, Mori M, Sugiyama K (2009) Hepatoprotective effects of flavonoids from shekwasha (Citrus depressa) against D-galactosamine-induced liver injury in rats. J Nutr Sci Vitaminol 56:60-67 
38. Harasstani OA, Moin S, Tham CL, Liew CY, Ismail N, Rajajendram R, Harith HH, Zakaria ZA, Mohamad AS, Sulaiman MR (2010) Flavonoid combinations cause synergistic inhibition of proinflammatory mediator secretion from lipopolysaccharide-induced RAW 264.7 cells. Inflamm Res 59:711-721

39. Lee YC, Cheng TH, Lee JS, Chen JH, Liao YC, Fong Y, Wu CH, Shih YW (2011) Nobiletin, a citrus flavonoid, suppresses invasion and migration involving FAK/PI3K/Akt and small GTPase signals in human gastric adenocarcinoma AGS cells. Mol Cell Biochem 347:103-115

40. Mulvihill EE, Assini JM, Sutherland BG, DiMattia AS, Khami M, Koppes JB, Sawyez CG, Whitman SC, Huff MW (2010) Naringenin decreases progression of atherosclerosis by improving dyslipidemia in high-fatfed low-density lipoprotein receptor-null mice. Arterioscl Throm Vas 30:742-748

41. Seki T, Kamiya T, Furukawa K, Azumi M, Ishizuka S, Takayama S, Nagase S, Arai H, Yamakuni T, Yaegashi N (2013) Nobiletin-rich Citrus reticulata peels, a kampo medicine for Alzheimer's disease: a case series. Geriatr Gerontol Int 13:236-238

42. Siahpoosh A, Javedani F (2012) Antioxidative capacity of Iranian Citrus deliciosa peels. Free Radic Antioxid 2:62-67

43. Jagdeep S, Shailja S, Arunachalam M (2014) In-vitro evaluation of bioactive compounds, anti-oxidant, lipid peroxidation and lipoxygenase inhibitory potential of Citrus karna L. peel extract. J Food Sci Technol 51:67-74

44. Padilla-Camberos E, Lazcano-Díaz E, Flores-Fernandez JM, Owolabi MS, Allen K, Villanueva-Rodríguez S (2014) Evaluation of the inhibition of carbohydrate hydrolyzing enzymes, the antioxidant activity, and the polyphenolic content of Citrus limetta peel extract. Sci World J 2014:1-4

45. Impellizzeri D, Bruschetta G, Di Paola R, Ahmad A, Campolo M, Cuzzocrea S, Esposito E, Navarra M (2014) The anti-inflammatory and antioxidant effects of bergamot juice extract (BJe) in an experimental model of inflammatory bowel disease. Clin Nutr 27 (pii: S0261-5614(14)00293-3)

46. Hirata T, Fujii M, Akita K, Yanaka N, Ogawa K, Kuroyanagi M, Hongo D (2009) Identification and physiological evaluation of the components from Citrus fruits as potential drugs for anti-corpulence and anticancer. Bioorgan Med Chem 17:25-28

47. Osawa T (1994) Novel natural antioxidants for utilization in food and biological systems. In: Uritani I, Garcia W, Mendoza EM (eds) Postharvest biochemistry of plant food-materials in the tropics. Japan Scientific Societies Press, Japan, pp 241-251

48. Cotelle N (2001) Role of flavonoids in oxidative stress. Curr Top Med Chem 1:569-590

49. Mari M, Colell A, Morales A, von Montfort C, Garcia-Ruiz C, FernandezCheca JC (2010) Redox control of liver function in health and disease. Antioxid Redox Sign 12:1295-1331

50. Barreca D, Bellocco E, Caristi C, Leuzzi U, Gattuso G (2010) Flavonoid composition and antioxidant activity of juices from chinotto (Citrus $\times$ myrtifolia Raf.) fruits at different ripening stages. J Argic Food Chem 58:3031-3036

51. Kim HG, Kim GS, Park S, Lee JH, Seo ON, Lee SJ, Kim JH, Shim JH, Abd El-Aty A, Jin JS (2012) Flavonoid profiling in three citrus varieties native to the Republic of Korea using liquid chromatography coupled with tandem mass spectrometry: contribution to overall antioxidant activity. Biomed Chromatogr 26:464-470

52. Sun Y, Qiao L, Shen Y, Jiang P, Chen J, Ye X (2013) Phytochemical profile and antioxidant activity of physiological drop of citrus fruits. J Food Sci 78:C37-C42

53. Aranganathan S, Nalini N (2009) Efficacy of the potential chemopreventive agent, hesperetin (citrus flavanone), on 1, 2-dimethylhydrazine induced colon carcinogenesis. Food Chem Toxicol 47:2594-2600

54. Kilci A, Gocmen D (2014) Phenolic acid composition, antioxidant activity and phenolic content of tarhana supplemented with oat flour. Food Chem 151:547-553

55. Ogiwara T, Satoh K, Negoro T, Okayasu H, Sakagami H, Fujisawa S (2003) Inhibition of NO production by activated macrophages by phenolcarboxylic acid monomers and polymers with radical scavenging activity. Anticancer Res 23:1317-1323

56. Abdel-Salam OM, Youness ER, Mohammed NA, Morsy SM, Omara EA Sleem AA (2014) Citric acid effects on brain and liver oxidative stress in lipopolysaccharide-treated mice. J Med Food 17:588-598
57. Korani MS, Farbood Y, Sarkaki A, Fathi Moghaddam H, Taghi Mansouri M (2014) Protective effects of gallic acid against chronic cerebral hypoperfusion-induced cognitive deficit and brain oxidative damage in rats. Eur J Pharmacol 733:62-67

58. Karamac M, Kosinska A, Pegg RB (2005) Comparison of radical-scavenging activities for selected phenolic acids. Polish J Food Nutri Sci 14:165-170

59. Jabri Karoui I, Marzouk B (2013) Characterization of bioactive compounds in Tunisian bitter orange (Citrus aurantium L.) peel and juice and determination of their antioxidant activities. Biomed Res Int 2013: 345415

60. Singh P, Shukla R, Prakash B, Kumar A, Singh S, Mishra PK, Dubey NK (2010) Chemical profile, antifungal, antiaflatoxigenic and antioxidant activity of Citrus maxima Burm. and Citrus sinensis (L.) Osbeck essential oils and their cyclic monoterpene, DL-limonene. Food Chem Toxicol 48:1734-1740

61. Choi HS, Song HS, Ukeda H, Sawamura M (2000) Radical-scavenging activities of citrus essential oils and their components: detection using 1, 1-diphenyl-2-picrylhydrazyl. J Agric Food Chem 48:4156-4161

62. Tundis R, Loizzo MR, Bonesi M, Menichini F, Mastellone V, Colica C, Menichini F (2012) Comparative study on the antioxidant capacity and cholinesterase inhibitory activity of Citrus aurantifolia Swingle, $C$. aurantium L., and C. bergamia Risso and Poit. peel essential oils. J Food Sci 77:H40-H46

63. Masamoto Y, Ando H, Murata Y, Shimoishi Y, Tada M, Takahata K (2003) Mushroom tyrosinase inhibitory activity of esculetin isolated from seeds of Euphorbia lathyris L. Biosci Biotech Biochem 67:631-634

64. Heiss E, Herhaus C, Klimo K, Bartsch H, Gerhauser C (2001) Nuclear factor kappa B is a molecular target for sulforaphane-mediated antiinflammatory mechanisms. J Biol Chem 276:32008-32015

65. Norihiro Y, Takahiro F, Hitoshi M, Takeshi O, Kunio S, Ron H (2014) Orange peel extract, containing high levels of polymethoxyflavonoid, suppressed UVB-induced COX-2 expression and PGE2 production in $\mathrm{HaCaT}$ cells through PPAR-c activation. Exp Dermatol 23:18-22

66. Bodet C, La V, Epifano F, Grenier D (2008) Naringenin has anti-inflammatory properties in macrophage and ex vivo human whole-blood models. J Periodontal Res 43:400-407

67. Yuasa K, Tada K, Harita G, Fujimoto T, Tsukayama M, Tsuji A (2011) Sudachitin, a polymethoxyflavone from Citrus sudachi, suppresses lipopolysaccharide-induced inflammatory responses in mouse macrophage-like RAW264 cells. Biosci Biotech Biochem 76:598-600

68. Wang AY, Zhou MY, Lin WC (2011) Antioxidative and anti-inflammatory properties of Citrus sulcata extracts. Food Chem 124:958-963

69. Yoshigai E, Machida T, Okuyama T, Mori M, Murase H, Yamanishi R, Okumura T, Ikeya Y, Nishino H, Nishizawa M (2013) Citrus nobiletin suppresses inducible nitric oxide synthase gene expression in interleukin-1 beta-treated hepatocytes. Biochem Biophys Res Commun 439:54-59

70. Kummer R, Fachini-Queiroz FC, Estevão-Silva CF, Grespan R, Silva EL, Bersani-Amado CA, Cuman RKN (2013) Evaluation of anti-inflammatory activity of Citrus latifolia Tanaka essential oil and limonene in experimental mouse models. Evid Based Complement Altern 2013:859083

71. Borgatti M, Mancini I, Bianchi N, Guerrini A, Lampronti I, Rossi D, Sacchetti G, Gambari R (2011) Bergamot (Citrus bergamia Risso) fruit extracts and identified components alter expression of interleukin 8 gene in cystic fibrosis bronchial epithelial cell lines. BMC Biochem 12:15

72. Lin S, Hirai S, Goto T, Sakamoto T, Takahashi N, Yano M, Sasaki T, Yu R, Kawada T (2013) Auraptene suppresses inflammatory responses in activated RAW264 macrophages by inhibiting p38 mitogen-activated protein kinase activation. Mol Nutr Food Res 57:1135-1144

73. Huang GJ, Deng JS, Liao JC, Hou WC, Wang SY, Sung PJ, Kuo YH (2012) Inducible nitric oxide synthase and cyclooxygenase-2 participate in anti-inflammatory activity of imperatorin from Glehnia littoralis. J Agric Food Chem 60:1673-1681

74. Sood S, Muthuraman A, Gill NS, Bali M, Sharma PD (2010) Role of 7 , 8-dimethoxycoumarin in anti-secretary and anti-inflammatory action on pyloric ligation-induced gastritis in rats. J Asian Nat Prod Res 12:593-599

75. Do-Hoon L, Kwang-II P, Hyeon-Soo P, Sang-Rim K, Arulkumar N, Jin-A K, Eun-Hee K, Won-Sup L, Young-Sool H, Hyon-Jong C, Su-Jin A, Gon-Sup K (2012) Flavonoids isolated from korea Citrus aurantium L. induce 
G2/M phase arrest and apoptosis in human gastric cancer AGS cells. Evid Based Complement Alternat 2012:1-11

76. Takuji T, Takahiro T, Mayu T, Toshiya K (2012) Cancer chemoprevention by citrus pulp and juices containing high amounts of $\beta$-cryptoxanthin and hesperidin. J Biomed Biotechnol 2012:1-10

77. Hang X, Chung SY, Shiming L, Huanyu J, Chi-Tang H, Trusha P (2009) Monodemethylated polymethoxyflavones from sweet orange (Citrus sinensis) peel inhibit growth of human lung cancer cells by apoptosis. Mol Nutr Food Res 53:398-406

78. Jin H, Lee WS, Yun JW, Jung JH, Yi SM, Kim HJ, Choi YH, Kim G, Jung JM, Ryu CH, Shin SC, Hong SC (2013) Flavonoids from Citrus unshiu Marc. inhibit cancer cell adhesion to endothelial cells by selective inhibition of VCAM-1. Oncol Rep 30:2336-2342

79. Ching-Shu L, Shiming L, ChengBin L, Yutaka M, Michiko S, Chi-Tang H, Min-Hsiung P (2013) Effective suppression of azoxymethane-induced aberrant crypt foci formation in mice with citrus peel flavonoids. Mol Nutr Food Res 57:551-555

80. Duraikannu A, Perumal S (2013) Inhibitory effect of naringenin (citrus flavonone) on $\mathrm{N}$-nitrosodiethylamine induced hepatocarcinogenesis in rats. Biochem Biophys Res Commun 434:203-209

81. Asghar G, Maryam N, Mahmood JT, Hamid Z (2012) The citrus flavonoid hesperidin induces p53 and inhibits NF-jB activation in order to trigger apoptosis in NALM-6 cells: involvement of PPARc-dependent mechanism. Eur J Nutr 51:39-46

82. Chang L, Jia S, Fu Y, Zhou T, Cao J, He Q, Yang B, Li X, Sun C, Su D, Zhu H, Chen K (2015) Ougan (Citrus reticulata cv. Suavissima) flavedo extract suppresses cancer motility by interfering with epithelial-to-mesenchymal transition in SKOV3 cells. Chin Med 10:14-23

83. Johnson JL, de Mejia EG (2013) Flavonoid apigenin modified gene expression associated with inflammation and cancer and induced apoptosis in human pancreatic cancer cells through inhibition of GSK3beta/NF-kappaB signaling cascade. Mol Nutr Food Res 57:2112-2127

84. Zhu X, Luo F, Zheng Y, Zhang J, Huang J, Sun C, Li X, Chen K (2013) Characterization, purification of poncirin from edible citrus ougan (Citrus reticulate $\mathrm{c} v$. suavissima) and its growth inhibitory effect on human gastric cancer cells SGC-7901. Int J Mol Sci 14:8684-8697

85. Steele VE, Moon RC, Lubet RA, Grubbs CJ, Reddy BS, Wargovich M (1994) Preclinical efficacy evaluation of potential chemopreventive agents in animal carcinogenesis models: methods and results from the $\mathrm{NCl}$ Chemoprevention Drug Development Program. J Cell Biochem 56:32-54

86. Wesołowska O, Wiśniewski J, Środa-Pomianek K, Bielawska-Pohl A, Paprocka M, Duś D, Duarte NL, Ferreira M-JU, Michalak K (2012) Multidrug resistance reversal and apoptosis induction in human colon cancer cells by some flavonoids present in citrus plants. J Nat Prod 75:1896-1902

87. Qiu P, Dong P, Guan H, Li S, Ho CT, Pan MH, McClements DJ, Xiao H (2010) Inhibitory effects of 5-hydroxy polymethoxyflavones on colon cancer cells. Mol Nutr Food Res 54:S244-S252

88. Kim J, Jayaprakasha GK, Vikram A, Patil BS (2012) Methyl nomilinate from citrus can modulate cell cycle regulators to induce cytotoxicity in human colon cancer (SW480) cells in vitro. Toxicol In Vitro 26:1216-1223

89. Kim J, Jayaprakasha GK, Patil BS (2013) Limonoids and their anti-proliferative and anti-aromatase properties in human breast cancer cells. Food Funct 4:258-265

90. Murthy KNC, Jayaprakasha G, Patil BS (2013) Citrus limonoids and curcumin additively inhibit human colon cancer cells. Food Funct 4:803-810

91. Prince M, Li Y, Childers A, Itoh K, Yamamoto M, Kleiner HE (2009) Comparison of citrus coumarins on carcinogen-detoxifying enzymes in Nrf2 knockout mice. Toxicol Lett 185:180-186

92. Patil JR, Jayaprakasha GK, Kim J, Murthy KN, Chetti MB, Nam SY, Patil BS (2013) 5-Geranyloxy-7-methoxycoumarin inhibits colon cancer (SW480) cells growth by inducing apoptosis. Planta Med 79:219-226

93. Narisawa T, Fukaura Y, Oshima S, Inakuma T, Yano M, Nishino H (1999) Chemoprevention by the oxygenated carotenoid beta-cryptoxanthin of N-methylnitrosourea-induced colon carcinogenesis in F344 rats. Jpn J Cancer Res: Gann 90:1061-1065

94. Mink PJ, Scrafford CG, Barraj LM, Harnack L, Hong CP, Nettleton JA, Jacobs DR (2007) Flavonoid intake and cardiovascular disease mortality: a prospective study in postmenopausal women. Am J Clin Nutr 85:895-909

95. Herwandhani P, Standie N, Yonika Arum L, Nindi W, Adam H (2013) Cardioprotective and hepatoprotective effects of Citrus hystrix peels extract on rats model. Asian Pacific J Trop Biomed 3:371-375

96. Lin Y, Vermeer MA, Bos W, van Buren L, Schuurbiers E, Miret-Catalan S, Trautwein EA (2011) Molecular structures of citrus flavonoids determine their effects on lipid metabolism in HepG2 cells by primarily suppressing apoB secretion. J Agric Food Chem 59:4496-4503

97. Yen JH, Weng CY, Li S, Lo YH, Pan MH, Fu SH, Ho CT, Wu MJ (2011) Citrus flavonoid 5-demethylnobiletin suppresses scavenger receptor expression in THP-1 cells and alters lipid homeostasis in HepG2 liver cells. Mol Nutr Food Res 55:733-748

98. Shen W, Xu Y, Lu YH (2012) Inhibitory effects of citrus flavonoids on starch digestion and antihyperglycemic effects in HepG2 cells. J Agric Food Chem 60:9609-9619

99. Akiyama S, Katsumata SI, Suzuki K, Ishimi Y, Wu J, Uehara M (2010) Dietary hesperidin exerts hypoglycemic and hypolipidemic effects in streptozotocin-induced marginal type 1 diabetic rats. J Clin Biochem Nutr 46:87

100. Liu L, Shan S, Zhang K, Ning ZQ, Lu XP, Cheng YY (2008) Naringenin and hesperetin, two flavonoids derived from Citrus aurantium up-regulate transcription of adiponectin. Phytother Res 22:1400-1403

101. Reshef N, Hayari Y, Goren C, Boaz M, Madar Z, Knobler H (2005) Antihypertensive Effect of Sweetie Fruit in Patients With Stage I Hypertension*. Am J Hypertens 18:1360-1363

102. Rizza S, Muniyappa R, lantorno M, Kim JA, Chen H, Pullikotil P, Senese N, Tesauro M, Lauro D, Cardillo C (2011) Citrus polyphenol hesperidin stimulates production of nitric oxide in endothelial cells while improving endothelial function and reducing inflammatory markers in patients with metabolic syndrome. J Clin Endocr Metab 96:E782-E792

103. Ming W, Hongwu Z, Chao Z, Hongmei J, Zhuo M, Zhongmei Z (2015) Identification of the chemical constituents in aqueous extract of Zhi-Qiao and evaluation of its antidepressant effect. Molecules 20:6925-6940

104. Hwang SL, Yen GC (2008) Neuroprotective effects of the citrus flavanones against $\mathrm{H} 2 \mathrm{O} 2$-induced cytotoxicity in PC12 cells. J Agric Food Chem 56:859-864

105. Hwang SL, Yen GC (2009) Modulation of Akt, JNK, and p38 activation is involved in citrus flavonoid-mediated cytoprotection of PC12 cells challenged by hydrogen peroxide. J Agric Food Chem 57:2576-2582

106. Okuyama S, Shimada N, Kaji M, Morita M, Miyoshi K, Minami S, Amakura Y, Yoshimura M, Yoshida T, Watanabe S, Nakajima M, Furukawa Y (2012) Heptamethoxyflavone, a citrus flavonoid, enhances brain-derived neurotrophic factor production and neurogenesis in the hippocampus following cerebral global ischemia in mice. Neurosci Lett 528:190-195

107. Epifano F, Molinaro G, Genovese S, Ngomba RT, Nicoletti F, Curini M (2008) Neuroprotective effect of prenyloxycoumarins from edible vegetables. Neurosci Lett 443:57-60

108. Okuyama S, Minami S, Shimada N, Makihata N, Nakajima M, Furukawa Y (2013) Anti-inflammatory and neuroprotective effects of auraptene, a citrus coumarin, following cerebral global ischemia in mice. Eur $J$ Pharmacol 699:118-123

109. Mahmoud MF, Hamdan DI, Wink M, El-Shazly AM (2013) Hepatoprotective effect of limonin, a natural limonoid from the seed of Citrus aurantium var. bigaradia, on D-galactosamine-induced liver injury in rats. N-S Arch Pharmacol 387:251-261

110. Espina L, Somolinos M, Loran S, Conchello P, García D, Pagán R (2011) Chemical composition of commercial citrus fruit essential oils and evaluation of their antimicrobial activity acting alone or in combined processes. Food Control 22:896-902

111. Vikram A, Jesudhasan PR, Jayaprakasha G, Pillai SD, Jayaraman A, Patil BS (2011) Citrus flavonoid represses Salmonella pathogenicity island 1 and motility in S. Typhimurium LT2. Int J Food Microbiol 145:28-36

112. Vikram A, Jayaprakasha G, Jesudhasan P, Pillai S, Patil B (2010) Suppression of bacterial cell-cell signalling, biofilm formation and type III secretion system by citrus flavonoids. J Appl Microbiol 109:515-527

113. Murata K, Takano S, Masuda M, linuma M, Matsuda H (2013) Antidegranulating activity in rat basophil leukemia RBL-2H3 cells of flavanone glycosides and their aglycones in citrus fruits. J Nat Med 67:643-646 
114. Itoh K, Hirata N, Masuda M, Naruto S, Murata K, Wakabayashi K, Matsuda H (2009) Inhibitory effects of Citrus hassaku extract and its flavanone glycosides on melanogenesis. Biol Pharm Bull 32:410-415

115. Eri O, Jun I, Tsutomu H, Makoto S, Ryuichiro S (2011) Anti-obesity and anti-hyperglycemic nomilin in mice fed a high-fat diet. Biochem Bioph Res Co 410:677-681

116. Seong-II K, Hye-Sun S, Hyo-Min K, Youn-Suk H, Seon-A Y, Seung-Woo K, Jeong-Hwan K, Moo-Han K, Hee-Chul K, Se-Jae K (2012) Immature Citrus sunki peel extract exhibits antiobesity effects by $\beta$-oxidation and lipolysis in high-fat diet-induced obese mice. Biol Pharm Bull 35:223-230

117. Xian-Mei Z, Gao-Yan W, Yang Z, Yu-Mei L, Jian-Xin L (2013) Inhibitory effects of alkaline extract of Citrus reticulata on pulmonary fibrosis. J Ethnopharmacol 146:372-378

118. Sung Hee $K$, Haeng Jeon H, Hye Jeong $Y$, Hyun Jin $K$, Min Jung $K$, Jae Ho P, Mi Jeong S, Myung Sunny K, Dae Young K, Jin-Taek H (2013) Citrus junos tanaka peel extract exerts antidiabetic effects via AMPK and PPAR- both in vitro and in vivo in mice fed a high-fat diet. Evid Based Complement Alternat 2013: 1-8

119. Madhyastha H, Yamaguchi M, Sameshima H, Ikenoue T, Maruyama M (2013) Revealing the mechanism of in vitro wound healing properties of Citrus tamurana extract. Biomed Res Int 2013:1-8

120. Aya I, Noriyuki S, Takashi T, Toshiki O, Hisayoshi N (2013) Antianxiety-like effects of Chimpi (dried Citrus peels) in the elevated open-platform test. Molecules 18:10014-10023

121. Li WQ, Kuriyama S, Li Q, Nagai M, Hozawa A, Nishino Y, Tsuji I (2010) Citrus consumption and cancer incidence: the Ohsaki cohort study. Int J Cancer 127:1913-1922
122. Nurk E, Refsum H, Drevon CA, Tell GS, Nygaard HA, Engedal K, Smith AD (2010) Cognitive performance among the elderly in relation to the intake of plant foods. The Hordaland Health Study. Br J Nutr 104:1190-1201

123. Sacco SM, Horcajada MN, Offord E (2013) Phytonutrients for bone health during ageing. Br J Clin Pharmacol 75:697-707

124. Deyhim F, Lopez E, Gonzalez J, Garcia M, Patil BS (2006) Citrus juice modulates antioxidant enzymes and lipid profiles in orchidectomized rats. J Med Food 9:422-426

125. Kim SS, Baik JS, Oh TH, Yoon WJ, Lee NH, Hyun CG (2008) Biological activities of Korean Citrus obovoides and Citrus natsudaidai essential oils against acne-inducing bacteria. Biosci Biotechnol Biochem 72:2507-2513

126. Wilkins MR, Widmer WW, Grohmann K, Cameron RG (2007) Hydrolysis of grapefruit peel waste with cellulase and pectinase enzymes. Bioresour Technol 98:1596-1601

127. Marin FR, Soler-Rivas C, Benavente-Garcia O, Castillo J, Perez-Alvarez JA (2007) By-products from different citrus processes as a source of customized functional fibres. Food Chem 100:736-741

128. Curl AL, Bailey GF (1961) The carotenoids of Navel oranges. J Food Sci 26:442-447

129. Minamisawa M, Yoshida S, Uzawa A (2014) The functional evaluation of waste yuzu (Citrus junos) seeds. Food Funct 5:330-336

\section{Publish with ChemistryCentral and every scientist can read your work free of charge \\ "Open access provides opportunities to our colleagues in other parts of the globe, by allowing anyone to view the content free of charge."}

W. Jeffery Hurst, The Hershey Company.

- available free of charge to the entire scientific community

- peer reviewed and published immediately upon acceptance

- cited in PubMed and archived on PubMed Central

- yours - you keep the copyright

Submit your manuscript here:

http://www.chemistrycentral.com/manuscript/
Chemistry Central 